\title{
Semantic Comprehension of Persian Endocentric and Exocentric Compounds in non-Persian Speakers
}

\author{
Sara Montazeri, Ali Afkhami, Atiyeh Kamyabi Gol \\ sara.montazeri92@gmail.com, aafkhami@ut.ac.ir, kamyabigol@um.ac.ir
}

\begin{abstract}
Semantic comprehension of Persian compound nouns in non-Persian speakers of TPSL $^{1}$ department was investigated using a cognitive-semantics approach. Regarding the semantic relationships between the bases of compound nouns, two were selected based on presence or lack of semantic head. Then, sufficient data were collected from different texts through a desk research method to make a frequency dictionary of endocentric and exocentric compound nouns based on the knowledge level of students. A definition-word pairing test was then selected and most frequent compound nouns ( 24 compound nouns) were identified and used for the test, developed and run in the form of an application for smart phones by an application developer and participants were provided with it. Overall, 888 data were collected from the test results and analyzed using standard statistical tests suggesting that due to presence of semantic head in endocentric compounds, speed and level of comprehending them was higher than exocentric compounds; moreover, a correlational relationship between comprehension of these compounds was identified. Therefore, the relationship between components of endocentric compounds was understood faster than exocentric compounds. Thus, applicability of CARIN ${ }^{2}$ theory was verified.
\end{abstract}

Indexing terms/Keywords: Comprehension, Compound noun, Endocentric, Exocentric, Persian-language learner, TPSL

Subject Classification: Cognitive-Semantics Linguistics

Language: English

Date of Submission: 2018-04-16

Date of Acceptance: 2018-04-20

Date of Publication: 2018-04-30

ISSN: 2348-3024

Volume: 09 Issue: 01

Journal: Journal of Advances in Linguistics

Website: https://cirworld.com

This work is licensed under a Creative Commons Attribution 4.0 International License.

\footnotetext{
${ }^{1}$ Teaching Persian as a Second Language of Ferdowsi University of Mashhad

${ }^{2}$ Competition among Relations in Nominals
} 


\section{Introduction}

In this research, the author compared comprehension of two groups of Persian compound nouns, namely endocentric compounds and exocentric compounds, in mid-level students in department of Teaching Persian as a Second Language (TPSL) at Ferdowsi University of Mashhad, based on a cognitive-semantics approach. In addition to comparing the level of comprehension, the author also compared the time duration for comprehending these two groups of nouns. Furthermore, we examined whether there is a significant relationship between Persian language learners' comprehension of endocentric compounds and that of exocentric compounds.

Semantic comprehension is debated and discussed in cognitive linguistics and it is of specific importance. Heretofore, comprehension of endocentric compounds and that of exocentric compounds are not compared in the field of cognitive linguistics. Moreover, no national and/ or foreign study has been devoted to comparing comprehension of these two categories of Persian compound nouns in Persian language learners and investigating the differences between these two groups of nouns, until today. Accordingly, the author of this research investigated these two categories of nouns and compared the level and time duration of semantic comprehension. Also, the relationship between comprehending the two categories of nouns in Persian language learners were identified and studied.

Since the subject of this research has not been studied in Persian language so far, some limitations and difficulties were encountered by the author. One of those limitations were lack of a frequency dictionary for endocentric and exocentric compound nouns. Hence, the author provided a list of endocentric and exocentric compound nouns, referring to Sabzevari's articles $(2012,2016)$ and dissertation (2009). Providing a list of these two categories of compound nouns and receiving instructions from mid-level professors of department of TPSL, the author selected 24 frequently-used compound nouns (12 endocentric compound nouns and 12 exocentric compound nouns) for designing definition-word pairing test, one of the word comprehension tests. Moreover, designing a test to examine the Persian language learners' comprehension, excluding the factors that influence comprehension was another difficulty of this research. Furthermore, a chronometer was supposed to be used for measuring the reaction time, but errors were possible and inaccurate results might be obtained; consequently, a developer of Android operating system applications was asked to design and run the test in the form of an application on smart phones. As the last limitation, since the participants were Persian learners from different nationalities (mainly Iraq), the author had difficulties communicating with some of them; so that the author sometimes spoke in English and received help from the professors in order to convey meanings and notions.

As a result, although studying cognitive issues requires advance and modern laboratory instruments, the author developed a test to measure and evaluate the level and time duration of comprehension of these two categories of compound nouns and run it in the form of an Android application for smart phones. By doing so, time duration and level of semantic comprehension were measured accurately and more precise results were obtained.

Throughout the present research, the author tried to answer the following questions:

1. Is there any significant difference between the level of comprehending endocentric compound nouns and that of exocentric ones?

2. Is there any significant difference between the time duration for definition-word pairing of endocentric compound nouns and that of exocentric ones?

3. Is there any significant relationship (correlation) between comprehension of endocentric compounds and that of exocentric compounds in Persian language learners? 
The theoretical framework of this research is cognitive linguistics and particularly, theory of Competition among Relations in Nominals (CARIN) is considered as the main framework. This research is devoted to investigating compound nouns. Compound nouns are categorized into two groups of analytic compounds and synthetic compounds and in this research, the author considered and investigated the former. Since compounding process is productive, several definitions are provided for it, among which some foreign and national definitions are presented below:

Lieber (2009: 43) proposes that compound nouns are composed of two (or more) bases, roots or stems. Tabatabayi (2003: 220) states that in compounding, at least two words are linked to each other and a new noun is created (e.g. ketab+khane, honar+mand+parvar). Shaghaghi (2007: 91-93) believes that in most definitions provided for compound nouns, they are considered as a combination of two free morphemes, but since different kinds of morphemes (free morphemes, bound morphemes, lexical morphemes, grammatical morphemes, and also simple and complex words) are observed in Persian compound nouns, those definitions are not comprehensive. Based on the semantic relationships between bases of compound nouns, they are categorized into four groups: endocentric, exocentric, appositive, dvandva (Shaghaghi, 2007: 123-124). Regarding presence or lack of semantic head in compound nouns as a criterion, the first two categories, i.e. endocentric compounds and exocentric compounds are investigated in this research:

\section{A. Endocentric Compounds}

Endocentric compounds are composed of two words, one of which is head and the other is modifier or restrictor. The head is located inside a compound noun and it has a hyponymy relationship with the noun. In Persian language, the head can be positioned on the right or left side of a compound (e.g. Shal Gardan: "Shal" is head and "Gardan" is modifier; Mush Khorma: "Mush" is head and "Khorma" is modifier (ibid)).

\section{B. Exocentric Compounds}

Exocentric compounds are composed of two words, none of which are head and they have no hyponymy-based relationship with the compound noun. An exocentric compound noun refers to an element that is not located within the compound noun (e.g. "Gardan Koloft" does not refer to "neck" (Gardan) or "stout" (Koloft) and it is an adjective applied to a person who has robust and stout neck; "Ab Siah" is a disease (ibid)).

\subsection{CARIN Theory}

Theory of Competition among Relations in Nominals (CARIN) was proposed by Gagne and Shoben in 1997. Gagne and Shoben were psycholinguists and they studied language, based on a cognitive approach. They investigated the influence of semantic relationships on comprehension of modifier-head combinations. These researchers believed that in order to comprehend and understand a compound composing of head and modifier, a semantic relationship should be identified and specified that can link concepts of the two components. Performing different experiments and examinations, they concluded that if the modifier of a compound is more frequent, the compound is easier to be comprehended. Moreover, they proposed a conceptual combination model, namely "Competition among Relations in Nominals", known as CARIN theory. According to this theory, semantic interpretation of a compound depends on the relationship between the components of that compound. In compound nouns, modifier, not head, determines the relationship and has the main role. In addition, when comprehending the compound nouns, several relations are activated in mind simultaneously; and among the relations activated and competing with each other, only one is selected.

\subsection{Background}

Before reviewing the related works and research, it should be noted that semantics of compound nouns has not been considered as much as other areas of linguistics. Some of foreign and national research are briefly reviewed and investigated in this section. A number of foreign studies on semantics of compound nouns are as follows: 
Bauer (1993: 30) believes that compounds are semantically categorized into four groups: endocentric, exocentric, appositive and dvandva. He distinguishes dvandva structures from conjunctive compositions. The compound nouns in which the whole compound semantic field is included within that of head are endocentric, e.g. "armchair" (a kind of chair). In exocentric compounds, there is no hyponymy relationship between the compound and the head, e.g. "redskin" (is a type of race, not skin).

In his book, Haspelmath (2002) states about semantics of compound nouns that the first compound component generally serves to modify and narrow the meaning of the second compound component. Thus, a lipstick is a special kind of stick (not a special kind of lip).

Gagne and Spalding (2004) believe that the type of relationship between components of a compound noun, determines the meaning of it. Indeed, type and role of the relationship is a key element in formation of a compound. In other words, the type of relationship between components of a compound has a deterministic role in specifying the compound meaning. Moreover, the relationship is supposed to be inferred by listener or reader, meaning the relationship cannot be identified based on the combination form.

Scalise, Fábregas and Forza (2009) conduct a research on exocentric compounds and state that endocentric or exocentric nature of a compound depends on the head concept. It means that if a compound has one or two heads, it is endocentric; and if it has no head, it is exocentric. Moreover, they proposed that modifier and head concepts can be divided into three sub-sections.

Analyzing new English compounds in her paper, Benczes (2013) proposes a discuss contrasting the traditional distinction between endocentric compounds and exocentric compounds and she removes the labels of "endocentric" and "exocentric". The researcher rejects the difference and distinction between these two categories of compounds and introduces an alternative approach to compounds semantics, according to cognitive linguistics.

Below are some of national studies on compounds semantics:

Shaki (1964: 47) categorized compound nouns into distinctive and non-distinctive, in terms of the semantic relationship between components and the whole composition. The meaning of distinctive compound nouns can be inferred based on lexical elements and also, on the syntactic relationship between them (e.g. Madar Shohar "mother-in-law"). In non-distinctive compound nouns, however, the meaning cannot be comprehended this way (e.g. Lak Posht "turtle"). Moreover, the researcher divided compound nouns into two groups of endocentric (Madar Bozorg "grandmother") and exocentric (Rish Sefid "grey-bearded"), according to the semantic relationships between the components.

Tehranisa (1978: 24) states that compound nouns have semantic unity, meaning these nouns are independent units that are used to name objects (things) (e.g. Shotor Morgh "ostrich"). In the word "Shotor Morgh", each of the two parts imply specific meanings and refer to a particular animal; although, reference of the compound noun "Shotor Morgh" differs from references of the two individual components. He also categorizes head-free compounds (e.g. Honar Pishe "actor") into four groups: 1. Nouns whose both stems have non-metaphorical meanings (e.g. Lak Posht); 2. Nouns whose both stems have metaphorical meanings (e.g. Sag Dast "stub axle"); 3. Nouns whose first stem has non-metaphorical meaning and second stem has metaphorical meaning (e.g. Shekar Panir "kind of confectionary"); and 4. Nouns whose first stem has metaphorical meaning and second stem has non-metaphorical meaning (e.g. Hezar Pa "millipede").

Tabatabayi (2003: 24) argues that compound nouns are categorized into three groups, based on meaning: endocentric, exocentric and dvandva. Referring to Spencer (1991: 311) and Katamba (1993: 321), the researcher considers the conjunctive structures as included by dvandvas.

Shaghaghi (2007: 123-124) categorized compound nouns into four groups according to semantic relationships between the components: endocentric, exocentric, appositive and dvandva. 
Badakhshan \& Judaki (2011) investigate semantic transparency and opacity of compound nouns (non-verbal element and present stem). They argue that a compound noun is composed of two or more lexical morphemes and it has at least two bases, both of which are words or morpheme roots. Transparent nouns are the words whose meanings can be inferred and comprehended from their sounds or structures. The meaning of opaque words, however, cannot be comprehended according to their forms. In this research, 500 compound nouns are collected from Dehkhoda dictionary and investigated. Finally, 14 grades of transparency are identified and introduced for those compound nouns.

Sabzevari (2012) states that there are two groups of compound nouns, according to presence or lack of head: endocentric and exocentric. Endocentric compound structures have head and they are transparent, in terms of meaning. Exocentric compound structures lack head and they are opaque, in terms of meaning. In the article, transparency and opacity are investigated, based on a cognitive approach.

In his article, Sabzevari (2012) investigated type and quality of semantic relationships in exocentric compounds, considering a cognitive-semantics approach. In that article, exocentric compounds are collected from daily conversations and different texts. He believes that in endocentric compounds, one of several semantic relationships is observed between the components while it is not true for exocentric compounds and no specific pattern is identified for them.

Karimi Doostan \& Vahid (2013) provide a semantic analysis for compound nouns. In their article, they investigate meanings of noun-noun compositions collected from Moin Encyclopedic Dictionary (1992), based on conceptual semantics approach. Moreover, they identified the main thematic roles in those collected data. Finally, 11 basic thematic roles are identified.

Sabzevari (2016) investigates meaning-formation and inference of conceptual patterns in Persian endocentric compound nouns. He believes that in endocentric compounds, the conceptual composition is of relational type and presence of a certain relationship may facilitate faster inference of an interpretation relative to the others and as a result, the meaning of that compound is comprehended faster. Therefore, the meaning of an endocentric compound is transparent and it is inferred from its inner components; however, in exocentric compounds, no relational interpretation occurs due to lack of head and modifier.

Therefore, semantic comprehension is one of the issues debated in cognitive linguistics and it is of great importance, but heretofore, level and time duration of comprehension of Persian endocentric and exocentric compounds are not compared in the field of cognitive linguistics. Moreover, no national and/ or foreign study has been devoted to comparing comprehension of these two categories of Persian compound nouns in Persian language learners and investigating the differences between these two groups of nouns until today. Accordingly, the author of this research investigated these two categories of nouns and compared the level and time duration of semantic comprehension. Also, the relationship between comprehending the two categories of nouns in Persian language learners were identified and studied.

\section{Methodology}

\subsection{Materials and Methods}

The method of this research is of desk-field type. Since no frequency dictionary is developed in Persian for the two groups of compound nouns, the author studied different frequency dictionaries, including Bi-Jan-khan Frequency Dictionary and finally the required data were collected from Sabzevari's dissertation (2009) and his articles $(2012,2016)$ in which the most comprehensive list of endocentric and exocentric compounds are provided. A list of endocentric and exocentric compound nouns were prepared and given to mid-level professors of TPSL department; the professors were asked to mark the compounds that were studied and learned by midlevel Persian learners, regarding the textbooks. Then, the most frequently used compounds of the two categories (i.e. the compounds that were more frequently marked) were selected to be used in the main test. In order to design an appropriate test, several tests (including lexical decision-making test, reading test, picture-word 
pairing and etc.) were investigated. Consequently, a test with the least interference with other linguistic aspects was selected and designed. Since semantic comprehension is considered and studied in this research, the participants should only comprehend and mention the words. Therefore, it was decided that the test to be designed in the form of definition-word pairing. The test -that is one of word comprehension tests- has been designed by the authors and also, has been run as an Android application on smart phone. Chronometer and paper-pencil tests were not used due to possibility of errors in measuring times of reacting to semantic comprehension. Hence, the authors used the above mentioned application that measures time in milliseconds (ms) (more details about the test are provided in section 2.3.4). Analyzing the participants' responses, the author used SPSS version 23 software and the main research tests (T-test and Pearson test) to examine the hypotheses. Moreover, Run test, One-Sample Kolmogorov-Smirnov test and Levene test were also performed to study and investigate the assumptions. Finally, the obtained results were used to answer the research questions.

\subsection{Research Variables}

The variables considered in the tests are as follow:

- Time as an independent variable

- Persian endocentric and exocentric compounds as dependent variables

\subsection{Test Run Method}

\subsubsection{Setting and Participants}

In May 2017, the test was distributed among the participants. The participants in this research include 37 midlevel Persian language learners of TPSL department at Ferdowsi University of Mashhad, who answered the test questions.

\subsubsection{Test Stimulants}

As mentioned before, given the fact that there is no frequency dictionary developed for compound nouns in Persian, the author collected the required data from Sabzevari's dissertation $(2009)$ and his articles $(2012,2016)$. The ultimately-selected data included 280 endocentric and 193 exocentric compound nouns. The list of endocentric compound nouns were provided in three A4 papers as 4 columns per page; and that of exocentric compounds were prepared in two pages. The two lists were given to the professors of TPSL department, who were experienced in teaching at mid-level. Among 16 professors who had the experience of teaching at midlevel, 12 (10 males and 2 females) accepted to participate in this research. The professors were asked to mark the compound nouns the meaning of which they think the Persian learners of TPSL department of Ferdowsi University of Mashhad know. Finally, the author measured frequencies of the compounds, based on the 12 series of responses provided by the professors, and selected the most frequent ones (the compounds that were more frequently marked).

The authors selected the most frequent compound nouns from the lists and used them to run definition-word pairing test. Reviewing the previous research in the field of semantic comprehension measurement and also, investigating the tests used by different researchers, the authors selected 24 compound nouns (12 exocentric compounds and 12 endocentric compounds) that had higher levels of frequency relative to the other nouns of the lists. Definitions of these 24 compound nouns were collected from 2-volume Dabestani encyclopedic dictionary (Shokri, 2003), Sokhan Compact Dictionary of Anvari (Anvari, 2003), Persian Encyclopedia for Kids and Teenagers (2001) and Dehkhoda Dictionary (2006). At the initial stage of the test and after registering the participants' personal information, a frequent stimulus similar to test stimulants was provided in order for the participants to get a better understanding about how to respond the questions. Since comprehension of compound nouns were examined throughout the test, the respondents were not required to perform specific activities, such as word productions; and they responded to the questions by comprehending and mentioning the words in definition-word pairing. The test developed as an Android application by an advanced application 
developer was provided to the respondents on two smart phones. The test was performed as follows: at the head of the page, definition of the compound noun was written and following that, four options were provided among which one was correct. The correct option was randomly placed among the others. In each page on the smart phone, one definition and four options were displayed and the respondents were supposed to click on Confirm and Continue bottom to go to the next page and the next question. The test stimulants were endocentric-exocentric, in the form of one in between. This way, the difficulty level of test stages remained similar and the time required for responding the two groups of nouns distributed in the stages.

\subsubsection{Test Run Procedure}

As stated before, the test for this research were developed as an application for android smart phones. The application was installed on two smart phones, namely LG Nexus 5 and LG G5. In May 2016, the test was given to Persian learners of TPSL department of Ferdowsi University of Mashhad. Two participants answered the tests simultaneously, and after they finished the test, two other participants were asked to answer the questions. Only those Persian learners who were inclined to participate in the test were asked to answer the questions. Before asking the students to answer the questions, the authors talked to the professors in order to appoint a proper date for the test run. In order to improve the quality of the test procedure, the Persian learners were asked to answer the questions in a vacant classroom to be isolated from any distracting noise or sound. Before the smart phones were given to the participants, the test objects, number of questions and the tips to be followed during the test were described to them. If the Persian learners could not understand the Persian descriptions and explanations, English language was used and also, there were no limitation or restriction regarding answering the questions. As mentioned before, one definition and four options were displayed on each page and at the bottom of the page, Confirm and Continue bottoms were provided. The next page appeared only when the respondents were assure of their responses. Moreover, it was not possible to return back to the previous page because one of the objectives of the test was to measure the time duration for comprehension; hence, if returning back to the previous pages was possible, accuracy of the results decreased. It should be noted that the participants required no specific skill to answer the questions and the application was easy to use. Before the test initiated, the participants' personal information were registered at the first page and then, the instruction for answering the question and an example were displayed at the second page in order for the participants to get a better understanding about responding procedure. Selecting "START" option, the participant could start the test and one definition and four options for it were provided in each separate page. Thus, 24 pages for 24 definitions were developed after the Example page and at the final page, the participants were appreciated and thanked for their participations. Furthermore, they were also thanked after they submitted smart phones to the researcher. The author was present at the classroom when the participants were answering the test and answered their pre- and post-test questions. Overall, 888 data were obtained from the tests (37 participants responded to 24 definition-word pairing tests and the words included 12 endocentric compound nouns and 12 exocentric compound nouns).

\section{Data Analysis}

\subsection{Descriptive Findings}

\section{A. Level of Comprehension in Persian language learners}

The level of comprehension of Persian endocentric compound nouns that is measured based on correct answers of the participants (definition-word pairing) is divided into three parts: Low, Medium, and High. Frequency and percentage for level of comprehending endocentric compounds are presented in Figure 1. 


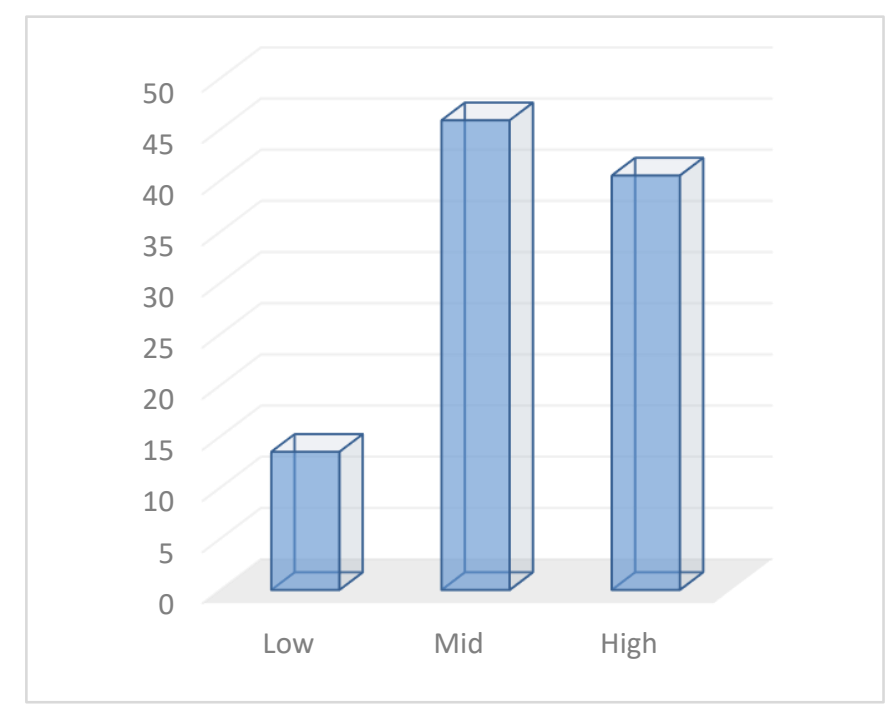

Figure 1: Frequency distribution of Persian learners according to "level of comprehending endocentric compounds"

In addition, level of comprehending exocentric compounds can be seen in Figure 2.

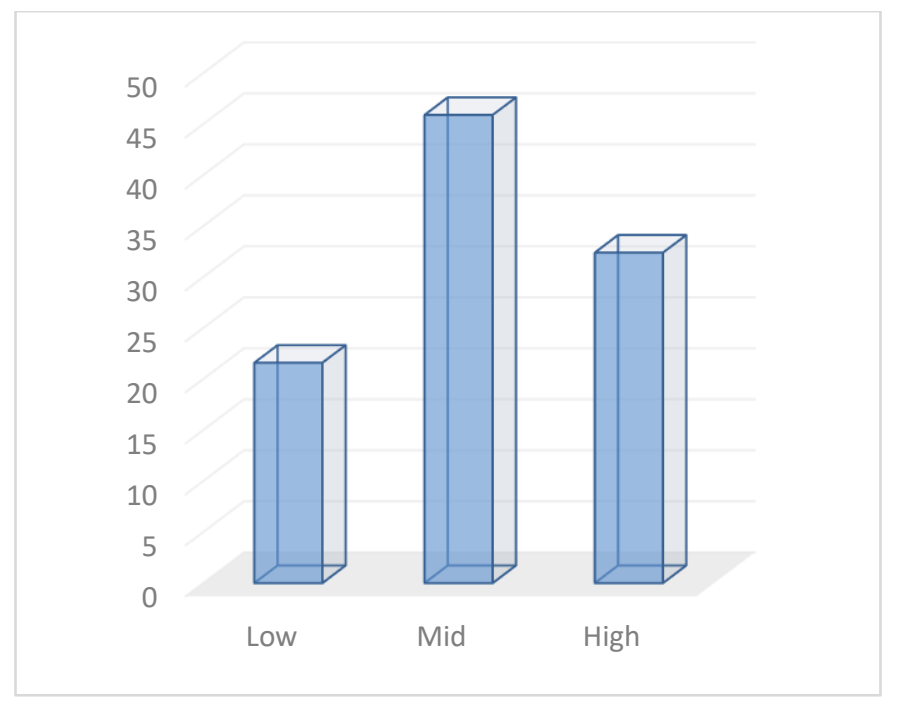

Figure 2: Frequency distribution of Persian learners according to "level of comprehending exocentric compounds"

Observing the figures above, it can be concluded that most of the Persian language learners were at medium level in comprehending endocentric and exocentric compound nouns.

\section{B. Time Duration for Definition-Word Pairing}

The average time duration required by the Persian language learners for pairing definitions and endocentric compound nouns was approximately $317 \mathrm{~s}$ ( 5 minutes and 28 seconds); while, the time consumed for pairing definitions and exocentric compound nouns was $374 \mathrm{~s}$ ( 6 minutes and 23 seconds). The findings are presented in Figure 3: 


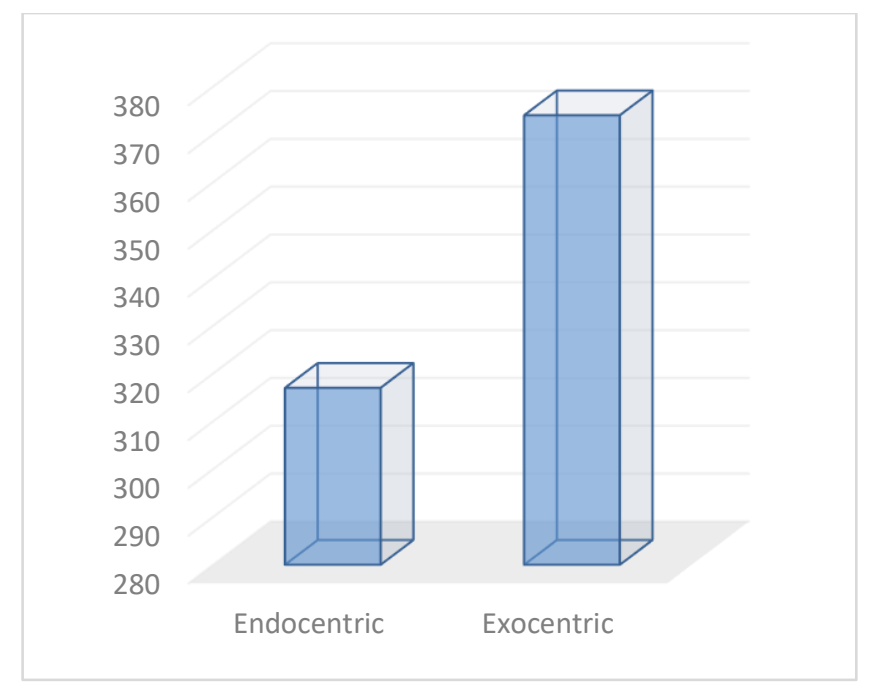

Figure 3: Distribution of average time duration of Persian learners according to "time of word-definition pairing"

It is also worth mentioning that age, sex and nationality are investigated in this research, too. The findings showed that the most Persian language learners were 20-24 years old constituting $40.5 \%$ of the whole Persian language students. Moreover, $86.5 \%$ of the students were male and only $13.5 \%$ of them were female. Finally, $70.3 \%$ of the Persian language learners were Iraqi.

After describing the variable, the author examined the research hypotheses (that are mainly comparative). The comparative tests are categorized under Parametric and Non-parametric labels. Parametric tests require specific assumptions that in comparative tests, are as follows:

A. Normal distribution (this presumption was measured and examined through Kolmogorov- Smirnov test)

According to the values obtained through Kolmogorov-Smirnov and significance level of higher than $5 \%$, it can be stated that the data do not have significant difference and they are normally distributed.

B. Independence of observations (this presumption was evaluated through Run test)

According to the values obtained from Run test and significance level of higher than $5 \%$, it can be stated that the data lack significant difference and presumption of independence of observations is verified.

C. The variables should be measured by interval scales.

In addition, the assumption of equality of variance in statistical population is also proposed but, it is usually ignored. Hence, all the above mentioned assumptions were measured and evaluated by appropriate statistical tests and the results suggested that all of the variables had the required conditions. According to the current situation of that time, T-test was performed for independent groups.

\subsection{Analytical Findings}

1. Is there any difference between the Persian language learners' comprehension of endocentric compounds and that of exocentric compounds?

The results from comparing level of comprehending endocentric compounds and exocentric compounds in the Persian language learners are presented in the following tables:

Paired Samples Statistics 


\begin{tabular}{||c||c||c||c||}
\hline \hline $\begin{array}{c}\text { standard } \\
\text { deviation }\end{array}$ & number & average & \\
\hline \hline 1.577 & 37 & 8.11 & comprehension of endocentric compounds \\
\hline 1.929 & 37 & 7.00 & comprehension of exocentric compounds \\
\hline
\end{tabular}

Table 1: Comparison of average level of Persian language learners' comprehension of endocentric and exocentric compounds

\section{Paired Samples Test}

\begin{tabular}{|c|c|c|c|c|}
\hline $\begin{array}{c}\text { significance } \\
\text { level }\end{array}$ & $\begin{array}{l}\text { degree of } \\
\text { freedom }\end{array}$ & $\begin{array}{l}\text { T-test } \\
\text { value }\end{array}$ & $\begin{array}{c}\text { Mean } \\
\text { difference }\end{array}$ & \\
\hline .001 & 36 & 3.473 & 1.11 & $\begin{array}{l}\text { comprehension of endocentric compounds } \\
\text { comprehension of exocentric compounds }\end{array}$ \\
\hline
\end{tabular}

Table 2: Results of T-test related to the Comparison of average level of Persian language learners' comprehension of endocentric and exocentric compounds

In tables above, the results of dependent T-test performed to compare the level of comprehending the two groups of compound nouns. The first group is endocentric compounds and the second group is exocentric compounds. According to the value obtained through T-test (3.473) and regarding the degree of freedom $(\mathrm{df}=$ 36) and error of less than 0.01 ( $\mathrm{Sig}=0.001$ ), it can be concluded that there is a significant difference between comprehending these two groups of compound nouns. Based on the results mentioned in tables, it can be stated that the average level of comprehending endocentric compounds was 8.11 and that of exocentric compounds was 7.0 in Persian language learners. Thus, the average level of comprehending endocentric compounds in Persian language learners was 1.11 scores higher than that of exocentric compounds.

2. Is there any significant difference between time duration required for pairing definitions and endocentric compounds and that of exocentric compounds?

The results from comparing time duration for pairing definitions and endocentric/ exocentric compound nouns are provided in two tables below:

Paired Samples Statistics

\begin{tabular}{||c||c||c||c||}
\hline \hline $\begin{array}{c}\text { standard } \\
\text { deviation }\end{array}$ & number & average & \\
\hline \hline 93678.385 & 37 & 317158.73 & $\begin{array}{c}\text { time duration for pairing definitions } \\
\text { and endocentric compound nouns }\end{array}$ \\
\hline \hline 106833.203 & 37 & 374446.32 & $\begin{array}{c}\text { time duration for pairing definitions } \\
\text { and exocentric compound nouns }\end{array}$ \\
\hline \hline
\end{tabular}


Table 3: Comparing average of time duration for pairing definitions and endocentric/ exocentric compound nouns

\section{Paired Samples Test}

\begin{tabular}{||c||c||c||c||c||}
\hline $\begin{array}{c}\text { significance } \\
\text { level }\end{array}$ & $\begin{array}{c}\text { degree } \\
\text { of } \\
\text { freedom }\end{array}$ & $\begin{array}{c}\text { T-test } \\
\text { value }\end{array}$ & $\begin{array}{c}\text { Mean } \\
\text { difference }\end{array}$ & \\
\hline \hline & 36 & -4.492 & -57287.59 & $\begin{array}{l}\text { time duration for pairing definitions and } \\
\text { endocentric compound nouns } \\
\text { time duration for pairing definitions and } \\
\text { exocentric compound nouns }\end{array}$ \\
\hline
\end{tabular}

Table 4: Results of T-test related to the comparing average of time duration for pairing definitions and endocentric/ exocentric compound nouns

In tables above, the results of dependent T-test performed to compare time duration for pairing definitions and two groups of compounds. The first group is endocentric compounds and the second group is exocentric compounds. According to the value obtained through T-test $(-4.492)$ and regarding the degree of freedom $(\mathrm{df}=$ $36)$, error of less than $0.01(\mathrm{Sig}=0.000)$ and reliability of higher than 0.99 , the author concluded that there is a significant difference between time duration required for pairing definitions and endocentric compounds and that of exocentric compounds. Based on the results mentioned in tables above, the average time for pairing definitions and endocentric compounds was $317 \mathrm{~s}$ and the average time for pairing definitions and exocentric compounds was $374 \mathrm{~s}$. Thus, the average time for definition-endocentric compound pairing was 57 seconds less than that for definition-exocentric compound pairing. In other words, definition-endocentric compound pairing was performed faster than definition-exocentric compound pairing.

3. Is there any significant relationship between the Persian language learners' comprehension of endocentric compounds and that of exocentric compounds?

The results of investigating relationship between the Persian language learners' comprehension of endocentric compounds and that of exocentric compounds are shown in table below:

\begin{tabular}{||c|c||c||}
\hline \hline $\begin{array}{c}\text { comprehension of } \\
\text { exocentric compounds }\end{array}$ & & \\
\hline \hline $.402\left(^{*}\right)$ & $\begin{array}{c}\text { Pearson } \\
\text { Correlation }\end{array}$ & $\begin{array}{c}\text { comprehension of } \\
\text { endocentric compounds }\end{array}$ \\
\hline \hline .014 & Sig. (2-tailed) & \\
\hline \hline 37 & $\mathrm{~N}$ & \\
\hline \hline
\end{tabular}

* Correlation is significant at the 0.05 level (2-tailed).

Table 5: Relationship between the Persian language learners' comprehension of endocentric compounds and that of exocentric compounds

According to the value obtained through Pearson test (0.402) and regarding an error of less than 0.05 (sig= 0.014 ) and reliability of higher than 0.95 , it can be stated that there is a significant relationship between the 
Persian language learners' comprehension of endocentric compounds and that of exocentric compounds. It should be noted that the positive value obtained through Pearson test suggested a direct relationship between the two variables, meaning that the higher the Persian learners' comprehension of endocentric compounds, the higher their comprehension of exocentric compounds is. In contrast, the lower the Persian learners' comprehension of endocentric compounds, the lower their comprehension of exocentric compounds would be.

\section{Discussion and Conclusion}

The results obtained from T-test suggested that the average level of comprehending endocentric compounds in the Persian language learners was higher than their average level of comprehending exocentric compound nouns; and also, the time required for pairing definitions and endocentric compounds was less than that for pairing definitions and exocentric compound nouns. Moreover, the results obtained from Pearson test showed that there exists a correlational relationship between the Persian learners' comprehension of endocentric compounds and that of exocentric compounds. It means that the higher the Persian learners' comprehension of endocentric compounds, the higher their comprehension of exocentric compounds is; and vice versa.

In endocentric compound nouns, a semantic head exists, but exocentric compound nouns lack semantic head. Hence, based on CARIN theory, it can be argued that: due to presence of semantic head in endocentric compounds, a relationship between modifier and head is identified; but since there is no semantic head in exocentric compounds, no relationship between the components of that compound can be recognized because no relationship can be formed due to lack of semantic head. Therefore, the level of comprehending endocentric compounds was found to be higher than that of exocentric compound nouns and also, endocentric compounds were comprehended faster than exocentric ones.

In brief, it can be stated that level of comprehending endocentric compounds in Persian learners of TPSL department were higher than their level of comprehending exocentric compounds. Also, less time was required for pairing definitions and endocentric compounds than for pairing definitions and exocentric compounds. The reason is that endocentric compound nouns are composed of two components, namely semantic head and modifier, and a relationship is identified between these two; however, since exocentric compound nouns lack semantic head, no relationship is recognized between their components. Therefore, the relationship can be comprehended in endocentric compounds faster than in exocentric ones.

\section{Conflicts of Interest}

The authors declare that no conflict exists.

\section{Funding Statement}

This research did not receive any specific grant from any funding agencies.

\section{References}

1. Amirghasemi, M. (2001). Persian Encyclopedia for Kids and Teenagers. Tehran: Dadar.

2. Anvari, H. (2003). Sokhan Compact Dictionary. Tehran: Sokhan Publication.

3. Badakhshan, E. \& Judaki, F (2011). Semantic Transparency and Opacity in Compound Nouns (Non-verbal element and present stem). Quarterly Scientific-Research Journal of Persian Language and Literature. School of Foreign Languages and Literature, Islamic Azad University of Sanandaj, the $3^{\text {rd }}$ year, No. 8.

4. Bauer, L. (1993). English Word Formation. Cambridge: Cambridge University Press. 
5. Benczes, R. (2013). On the non-viability of the endocentric-exocentric distinction: Evidence from linguistic creativity. EXELL (Explorations in English Language and Linguistics. 1.1 (2013): 3-18.

6. Gagne, C. L. \& Shoben E. J. (1997). The Influence of Thematic Relations on the Comprehension of modifiernoun combinations, Journal of Experimental Psychology: Learning, Memory, and Cognition, No. 23

7. Gagne, C. L \& Spalding T. L. (2004). Effect of relation availability on the interpretation and access of familiar noun-noun compounds. Brain and Language 90 (2004) 478-486.

8. Haspelmath, M. (2002). Understanding Morphology. London: Arnold.

9. Karimi Doostan, Q. and Vahid, A. (2013). Semantic Analysis of Noun- Noun Compounds in Persian Language. Linguistics Research, the $5^{\text {th }}$ Year, No. 1, 65-82.

10. Katamba, F (1993). Morphology, Macmillan: Macmillan Press LTD.

11. Lieber, R. (2009). Introducing Morphology. Cambridge University Press.

12. Sabzevari, M. (2009). Semantic Combinability in Modern Persian Compound Nouns. Ph.D. Thesis. Tehran: Institute for Humanities and Cultural Studies.

13. Sabzevari, M. (2012). Semantic Transparency and Opacity in Persian Compound Nouns from a Cognitive Perspective. Quarterly of Language Inquires, $4^{\text {th }}$, No. 3 (Serial 15), 55-73.

14. Sabzevari, M. (2012). Explaining and Analyzing Semantic Relationships in Standard Persian Exocentric Compound Nouns. Critical Research Journal of Human Science Texts and Plans, Institute for Humanities and Cultural Studies. The $12^{\text {th }}$ Year, No. 1, 45-61.

15. Sabzevari, M. (2016). Investigation of Meaning Formation and Inference of Conceptual Patterns in Persian Endocentric Compound Nouns. Quarterly Scientific- Research Journal of Linguistics Research. Alzahra University.

16. Scalise S. et al. (2009). Exocentricity in Compounding, Gengo Kenkyu, 135: 49-84.

17. Shaghaghi, V. (2007). An Introduction to Morphology. Tehran: Organization of Studies and Compilation of Books in Humanities Science for Universities (SAMT).

18. Shaki, M. (1964). A Study on Nominal Compoundsin Neo-Persian. Praha: Nakladatelstvi, Cekoslovenske VED.

19. Shokri, G. (2003). Encyclopedic Dictionary of Dabestani. Tehran: Institute for Humanities and Cultural Studies.

20. Sotude, Q., Mehraki, I. and Soltani, A. (2006). Dictionary: Intermediate Dehkhod Dictionary. Tehran: University of Tehran Publication.

21. Tabatabayi, A. (2003). Compound Nouns and Adjectives in Persian Language. Tehran: University Publication Center.

22. Tehranisa, S.A. (1987). A Syntactic and Semantic Analysis of Compound Nouns in Persian. Ph.D Dissertation. University of Michigan. 